\title{
A Precise Technique for Measurement of Optical-Fiber Hole Concentricity in the Ferrule of an Optical Connector
}

Federal Manufacturing \& Technologies

P. E. Klingsporn

KCP-613-5710

Published December 1996

\section{Topical Report}

Approved for public release; distribution is unlimited.

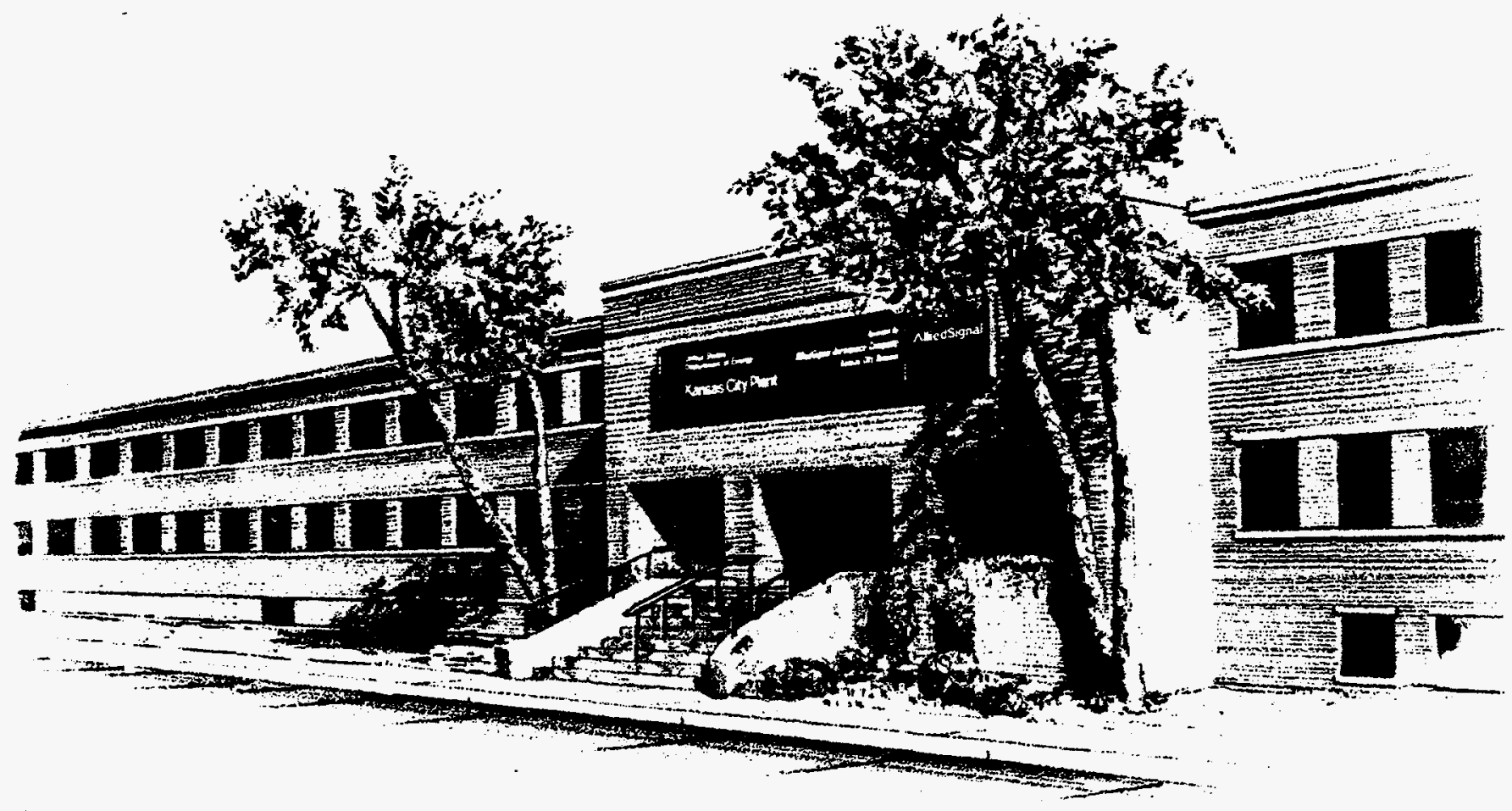




\section{DISCLAIMER}

Portions of this document may be illegible in electronic image products. Images are produced from the best available original document. 


\section{DISCLAIMER}

This report was prepared as an account of work sponsored by an agency of the United States Government. Neither the United States Government nor any agency thereof, nor any of their employees, makes any warranty, express or implied, or assumes any legal liability or responsibility for the accuracy, completeness, or usefulness of any information, apparatus, product, or process disclosed, or represents that its use would not infringe privately owned rights. Reference herein to any specific commercial product, process, or service by trade names, trademark, manufacturer, or otherwise, does not necessarily constitute or imply its endorsement, recommendation, or favoring by the United States Government or any agency thereof. The views and opinions of authors expressed herein do not necessarily state or reflect those of the United States Government or any agency thereof.

Printed in the United States of America.

This report has been reproduced from the best available copy.

Available to DOE and DOE contractors from the Office of Scientific and Technical Information, P. O. Box 62, Oak Ridge, Tennessee 37831; prices available from (615) 576-8401, FTS 626-8401.

Available to the public from the National Technical Information Service, U. S. Department of Commerce, 5285 Port Royal Rd., Springfield, Virginia 22161.

AlliedSignal Inc. Federal Manufacturing Department of Energy under Contract Number \& Technologies DE-ACO4-76-DP00613. 
KCP-613-5710

Distribution Category UC-706

Approved for public release; distribution is unlimited.

A PRECISE TECHNIQUE FOR MEASUREMENT OF OPTICALFIBER HOLE CONCENTRICITY IN THE FERRULE OF AN OPTICAL CONNECTOR

P. E. Klingsporn

Published December 1996

Topical Report

P. E. Klingsporn, Project Leader 


\section{Contents}

Section

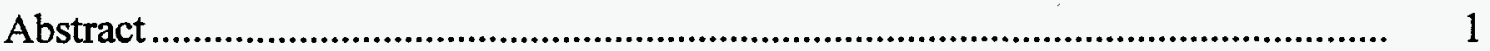

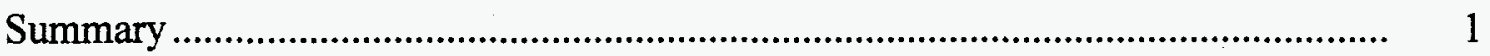

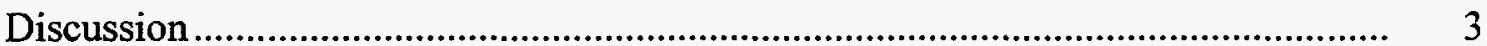

Scope and Purpose ........................................................................... 3

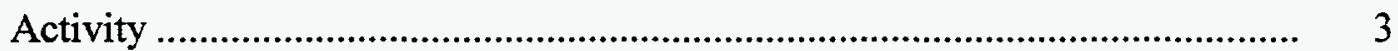

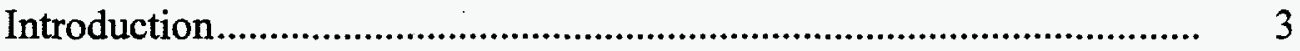

Transmitted Light Energy as a Function of Cylinder or Pin

Location

Measurements With a Convergent Light Beam ................................. 9

Repeatability Measurements ............................................................ 11

Measurements With a Collimated Light Beam.................................. 18

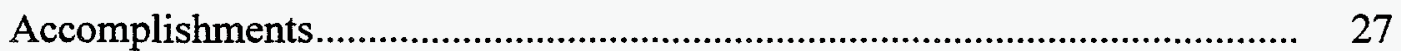

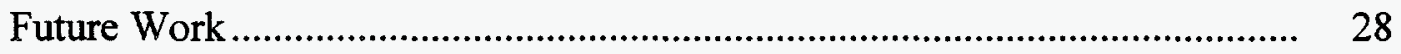

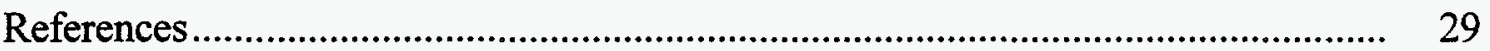




\section{Illustrations}

Figure

Page

1 (a) A Cylinder Containing a Longitudinal Hole, Parallel to the Axis of the Cylinder, But the Hole Center and Cylinder Center Are Not Concentric, as Indicated in (b) Which Shows a Plane Perpendicular to the Cylinder Axis.

2 Schematic View of the Arrangement Used to Measure the Degree of Concentricity of a Hole in a Cylinder, Relative to the Outer Cylindrical Surface

3 Geometry Used in Deriving Equation 6 of the Text

4 Schematic View of the Arrangement Used to Provide a Slightly

Convergent Light Beam, in the Setup of Figure 2, Through

Which the Cylindrical Body Passes....

5 Theoretical and Measured Ratio of Transmitted Light Beam Energy

to Unobstructed Beam Energy as a Function of Position of

Cylindrical Body in Path of Light Beam

6 Cross Section of a Ferrule Containing a Hole Whose Degree of

Concentricity is the Distance C.

7 Theoretical and Measured Concentricity of Ferrule/Hole as a

Function of Angular Orientation of Ferrule About Its Vertical Axis

8 Schematic View of Lens/Fiber Arrangement for Providing a Collimated Light Beam, in the Setup of Figure 2, Through Which the Cylindrical Body Passes.

9 Graphic Representation of Equation 17 of the Text 


\section{Tables}

1 Repeatability Measurements for Passage of a 0.119-Inch Diameter Ferrule In/Out of Fiber Light Beam ............................................................... $\quad 12$

2 Repeatability Measurements for Passage of an 0.018-Inch Diameter Pin In/Out of the Fiber Light Beam

3 Measurement Repeatability for Location of an 0.018-Inch Diameter Pin Center Relative to Center of a 0.119-Inch Diameter Ferrule Containing the Pin

4 Measurement Repeatability for Location of a 0.0188-Inch Diameter Pin Center Relative to Center of an 0.0848-Inch Diameter Ferrule Containing the Pin

5 Repeatability of Concentricity Measurement in a Given Plane of Ferrule/Pin Based on Equation 17 


\begin{abstract}
A precise optical method was developed for measuring the concentricity of a longitudinal hole in a cylinder relative to the outer cylindrical surface. The work was done to provide improved accuracy over existing methods for measuring the concentricity of an optical fiber relative to the outer ferrule diameter in an optical connector. Fiber concentricity is very important for reliable coupling of high optical power densities from one connectorized fiber cable to another. The technique involves the use of a laser interferometer to measure the passage of the ferrule into and out of a light beam whose attenuated energy is measured simultaneously to high precision. Combined measurements of the passage of a precisely fit pin or fiber in the ferrule hole through the light beam allow the concentricity of the fiber hole to be measured relative to the outer ferrule diameter. Repeatability measurements were made under different experimental arrangements, with both a collimated light beam and a slightly convergent light beam. Depending on the particular arrangement, the standard deviation for concentricity measurement in a given plane of the ferrule ranged from $2.37 \mu$ in. to 4.19 uin.
\end{abstract}

\title{
Summary
}

An optical noncontact interferometric method was developed for measuring the concentricity of a longitudinal hole in a cylinder with respect to the outer cylindrical surface. This work was undertaken to provide greater accuracy than that afforded by other methods of measuring the concentricity of an optical fiber in an optical connector ferrule, with respect to the outer ferrule surface. When coupling optical energy from one fiber cable to another via a mated pair of optical connectors the degree of concentricity of each fiber in its ferrule is not only important for optimum transmission efficiency but also to avoid fiber face damage during coupling of high optical power densities such as those that exist in a DOI (direct optical initiation) system.

In the present method devised for measuring concentricity of a hole in a cylinder, a lensing arrangement is used to form a small-diameter light beam using a light-emitting diode (LED) of very stable energy. The light beam energy is measured with a very stable, sensitive detector. Mechanical slides with precision movement are used to move the cylindrical ferrule into the path of the light beam, and the detector provides a precise measure of the decrease in light beam energy as the ferrule movement obscures a portion of the beam. The actual position of the ferrule as it is moved is measured very accurately with a laser interferometer. In this way, the position of the ferrule in the light beam is known as a function of the light energy that it obscures, and therefore the center of the ferrule can be determined as the ferrule is moved in and out of the path of the light beam. Corresponding measurements are made as a close-fitting pin or fiber inserted in the hole is moved in, through, and out of the light beam. The concentricity of 
the ferrule hole with respect to the ferrule outer diameter is determined from the difference between the interferometrically measured ferrule center and the measured fiber center in the path of the light beam.

Various experimental arrangements were used to demonstrate the concept for concentricity measurement and to obtain data on repeatability of the measurements. In one set of measurements a steel ferrule of outer diameter 0.1190 inch containing a hole of diameter 0.0188 inch was used. The standard deviation for measurement of hole concentricity was determined to be $3.15 \mu \mathrm{in}$., using a setup in which one lens was used to form a slightly convergent light beam. In another set of experiments, two lenses were used to provide a nearly collimated light beam. With this arrangement the repeatability measurement for concentricity of an 0.0848 -inch diameter ferrule containing a 0.0188 -inch diameter hole was determined to be $2.37 \mu$ in. 


\section{Discussion}

\section{Scope and Purpose}

A technique was developed for measuring the concentricity of a hole in a cylinder with respect to the outer surface. The endeavor was undertaken to provide an accurate means of measuring the concentricity of the optical fiber hole relative to the outer ferrule diameter in an optical connector. The degree of concentricity of a fiber with respect to the optical connector ferrule diameter is important, not only in achieving maximum coupling from one fiber to another, but also in reducing the possibility of damage at the fiber faces during the transfer of high optical power densities in the range of $\mathrm{GW} / \mathrm{cm}^{-2}$ that exist in a DOI (direct optical initiation) system.

\section{Activity}

\section{Introduction}

Consider a rod or cylinder with a hole on or near its longitudinal axis as indicated in Figure 1a. One way of determining the concentricity of the hole with respect to the outer cylindrical surface is to view the end with a microscope, or make a photograph of the end and measure the radial distance from the cylindrical periphery to the edge of the hole at various angular locations. For precise determinations this method is lacking because of uncertainties in knowing the outer edge in the plane of the end and uncertainties in knowing the edge of the hole. That is, the entrance of the hole always contains a degree of jaggedness, if only on a microscale, that lends uncertainty in the hole peripheral location for comparison with the cylindrical outer surface. However, in many applications the microscale of the jaggedness is of the same order as the preciseness with which the concentricity is desired to be known. This is the case when considering precise alignment in mating one optical fiber connector to another for optimum coupling of energy from one fiber to the other. For maximum transfer of energy, the mating fiber centers must be as nearly coincident as possible. The degree of colinearity depends on the concentricity of the holes holding the fibers in the connectors and on the precision of the barrel that holds the connectors in relative alignment.

It is believed that hole concentricity should be $3 \mu \mathrm{m}$ in a given connector to meet the needs of coupling high optical power density from one fiber to another in the DOI system for advanced optical firing. The closest known method for concentricity measurement of this type involves the use of dial indicators in contact with the outer periphery and with a pin inserted in the hole. ${ }^{1,2}$ Dial indicators are limited in accuracy to a few micrometers. For small holes, the pin may deflect under the load of the indicator probe, which results in inaccuracy. 


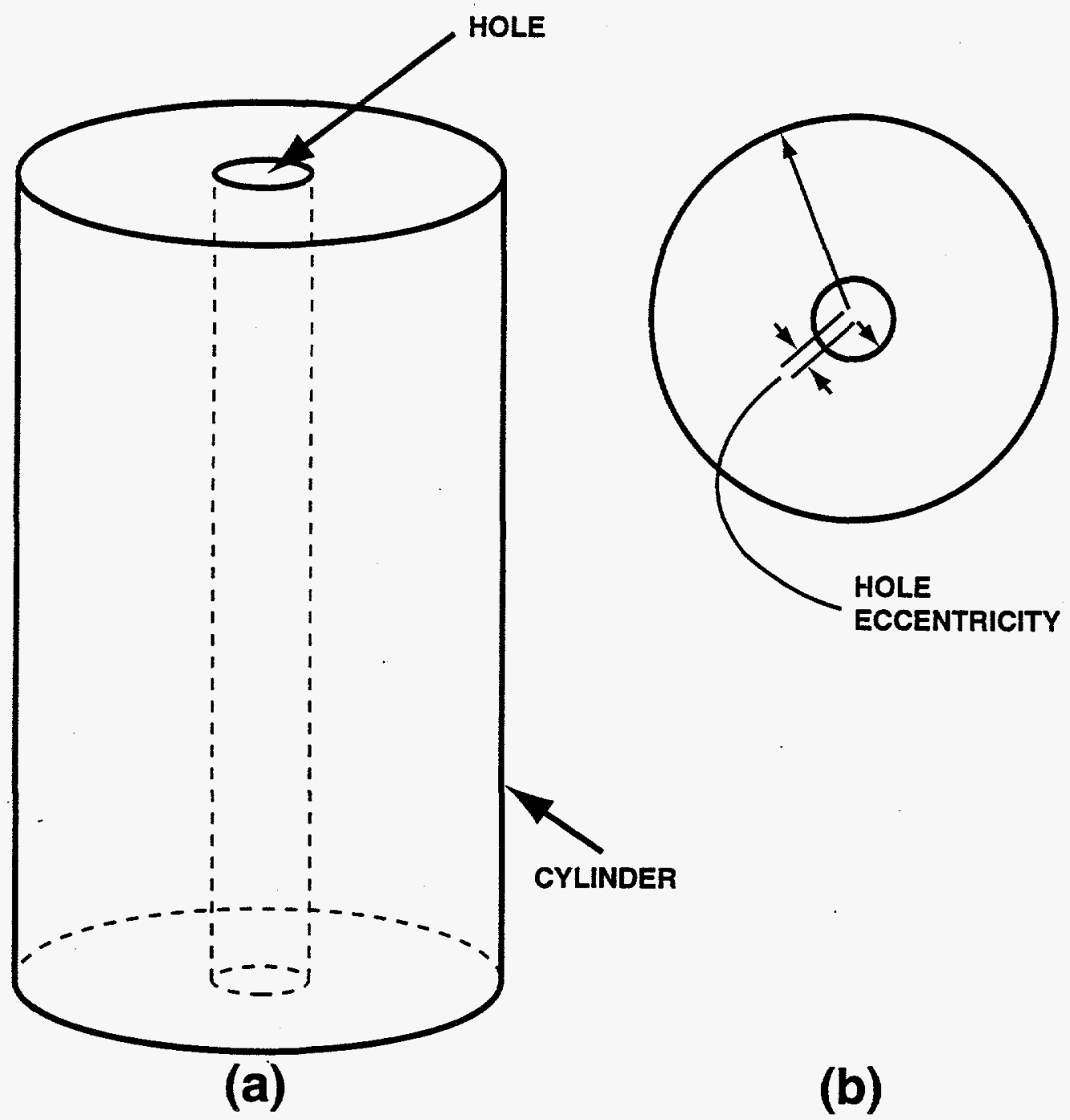

Figure 1. (a) A Cylinder Containing a Longitudinal Hole, Parallel to the Axis of the Cylinder, But the Hole Center and Cylinder Center Are Not Concentric, as Indicated in (b) Which Shows a Plane Perpendicular to the Cylinder Axis

A coordinate measuring machine could in principle be used to define the hole surface mathematically and compare it to the outer surface, but this method is limited to holes above a certain diameter determined by the size of the coordinate measuring probe. For hole depth-todiameter ratios in the range of four, the minimum hole diameter is approximately 0.050 inch. Holes in optical connections are generally 0.016 inch or smaller in diameter. 
The optical noncontact interferometric method described below for hole concentricity measurement overcomes the disadvantages of the other methods. Moreover, the specific measurement technique provides an accuracy at least one order of magnitude better than the use of dial indicators.

Consider the arrangement shown schematically in Figure 2 in which a cylinder with a hole on or near its axis is mounted with axis vertical on a vertical slide $V_{s}$. The vertical slide, in turn, is mounted on a horizontal slide $\mathrm{H}_{\mathrm{s}}$. Movement of the horizontal slide in the $\mathrm{x}$ direction of Figure 2 is measured accurately with a laser interferometer. The ends of two optical fibers are positioned coaxially along the y-axis of Figure 2, so that the beam emitted by one and received by the other is directed along the $\mathrm{y}$ axis. As the cylinder containing the hole is moved along the $\mathrm{x}$ axis, it will interrupt the light beam, causing the detector to register a continually decreasing light level. As the body is continued to be moved in the same direction along the $x$-axis, it will begin to pass out of the path of the light beam and the detector will register an increasing light level. Let $\mathrm{x}_{1}$ be the interferometer reading when the cylindrical body has moved into the path of the light beam such that the detected light is, for example, $\mathrm{P} / 2$, where $\mathrm{P}$ is the light level of the unobstructed beam; similarly, let $\mathrm{X}_{2}$ be the interferometer reading as the body passes out of the path of the light beam, at which the power level is again $\mathrm{P} / 2$. The $\mathrm{x}$-coordinate $\mathrm{x}_{\mathrm{c}}$ corresponding to the position of the body when it is centered in the path of the light beam is

$$
x_{c}=\left(x_{1}+x_{2}\right) / 2 .
$$

Next, the vertical slide is used to position the body with pin in the hole so that the pin moves through the light beam path as the horizontal slide is moved. Let $\mathrm{x}_{3}$ be the $\mathrm{x}$ coordinate position as measured by the interferometer when the pin is positioned such that the light level is one half the unobstructed value, and, as the pin passes out through the light path, let $\mathrm{x}_{4}$ be the interferometer reading when the light level is again one half its unobstructed value. Then, the $\mathrm{x}$ coordinate corresponding to a centered position of the pin in the light beam is

$$
x_{p}=\left(x_{3}+x_{4}\right) / 2 .
$$

Therefore, the degree of concentricity, $\mathrm{c}$, is

$$
\begin{aligned}
c & =x_{c}-x_{p} \\
& =\left(x_{1}+x_{2}-x_{3}-x_{4}\right) / 2 .
\end{aligned}
$$

Determination of the concentricity in any other longitudinal plane of the cylinder can be made by first rotating the cylinder about the vertical (z-axis) in Figure 2 and then following the procedure outlined above. 


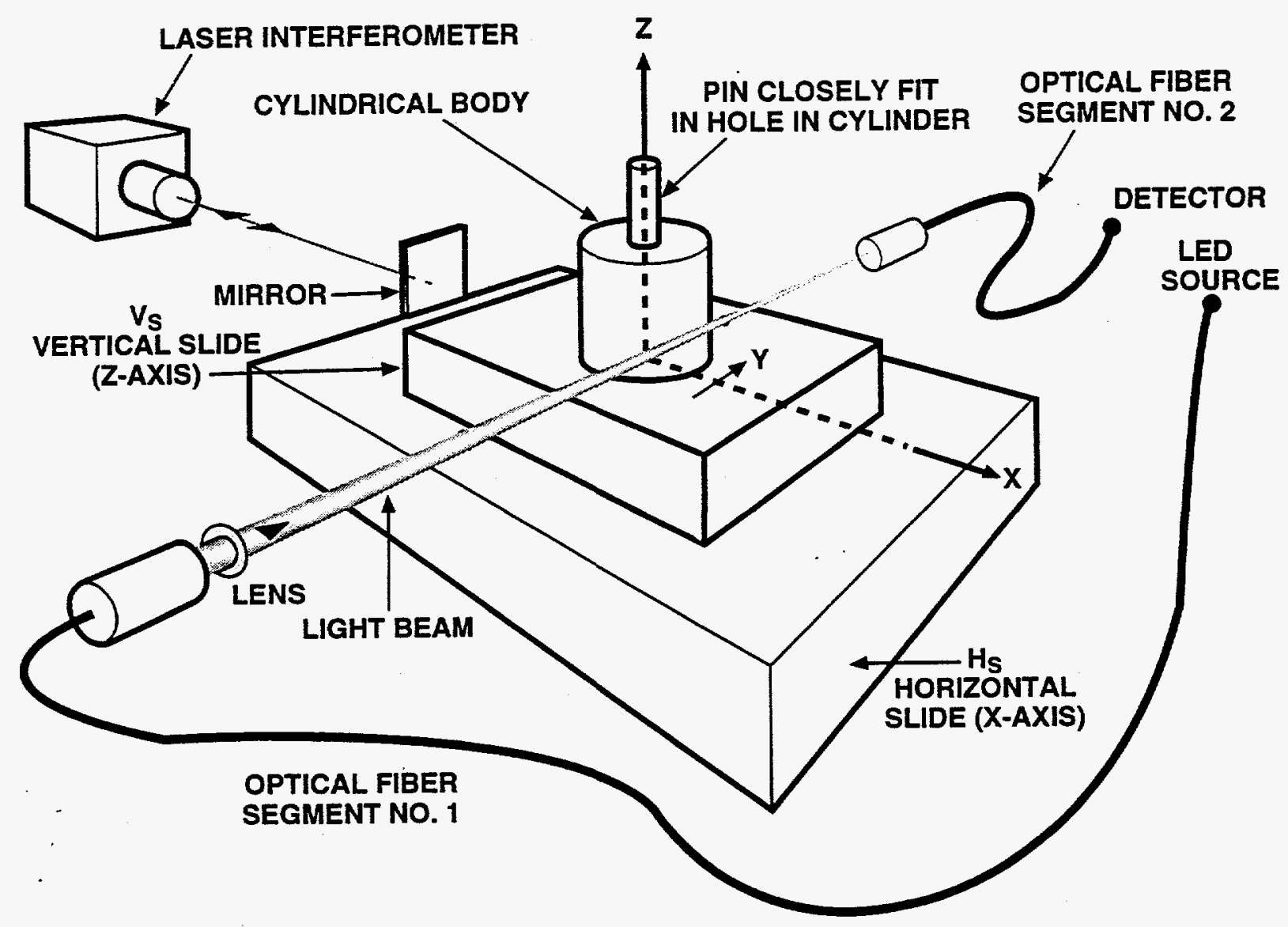

Figure 2. Schematic View of the Arrangement Used to Measure the Degree of Concentricity of a Hole in a Cylinder, Relative to the Outer Cylindrical Surface

It is assumed that the out-of-roundness of the cylindrical outer surface in Figure 2 is small compared to the eccentricity of the hole. If this is not the case, the measurements $x_{1}, x_{2}$ referred to above will reflect the out-of-roundness. However, if pairs $x_{1}, x_{2}$ are measured for each of several angular orientations of the cylinder about the $z$ axis, throughout a full rotation, then a best-fit circle can be obtained mathematically from the data. To determine concentricity, the measurements $x_{3}, x_{4}$ in a given longitudinal plane are then referenced to the center of the best-fit circle. Furthermore, the pin inserted in the hole must be a precision gage pin with out-ofroundness less than the hole concentricity.

The Hewlett-Packard laser interferometer system consisted of an HP5500C laser head, HP10562A single beam interferometer, and HP5505A laser display. For measurement of the transmitted light beam energy, an HP8153A lightware multimeter was used which contained an HP81530A silicon sensor and an HP81541 light emitting diode. 


\section{Transmitted Light Energy as a Function of Cylinder or Pin Location}

As the cylinder (or pin) in Figure 2 is moved in the $\mathrm{x}$ direction through the path of the light beam, the ratio of transmitted light energy to the unobstructed beam energy can be determined as a function of the cylinder location with the aid of the geometry in Figure 3. The light beam of radius $\mathrm{r}$ is assumed to have uniform intensity in its cross section. Let the cylinder (or pin) be at an arbitrary location designated by the distance $\mathrm{x}$. The area $\mathrm{A}_{\mathrm{ob}}$ of the light beam obstructed by the cylinder can be expressed in terms of $\theta$ and $r$ as

$$
\begin{aligned}
A_{o b} & =\pi r^{2}\left(\frac{2 r \theta}{2 \pi r}\right)-r \cos \theta r \sin \theta \\
& =r^{2} \theta-r^{2} \cos \theta \sin \theta .
\end{aligned}
$$

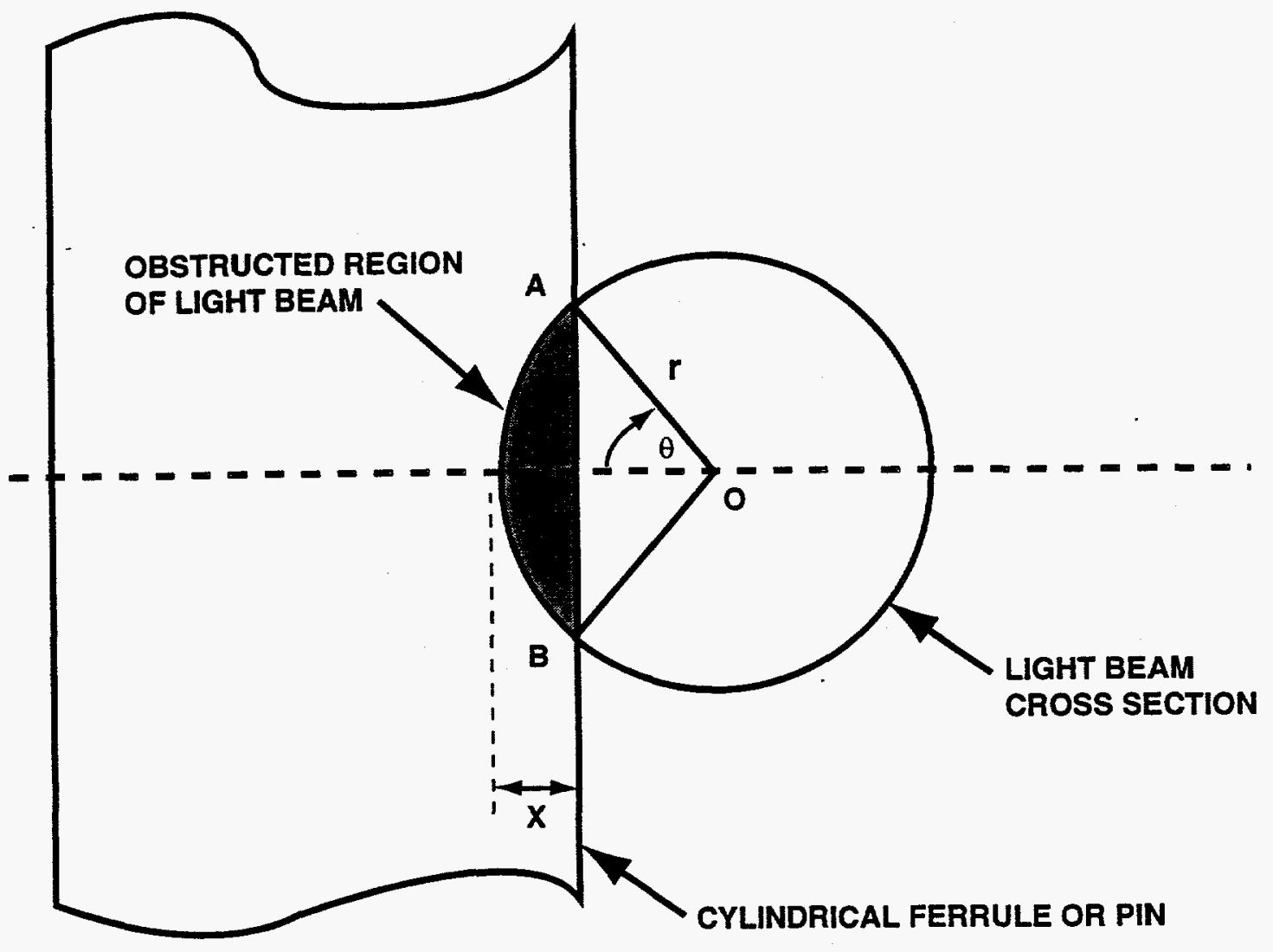

Figure 3. Geometry Used in Deriving Equation 6 of the Text. (The axis of the light beam is perpendicular to the plane of the page, and the axis of the cylindrical body lies in the plane of the page. Movement of the cylindrical body is from left to right, along the horizontal $x$-axis of Figure 2.) 
The ratio of obstructed energy to the total unobstructed energy in the beam is

$$
\frac{\mathrm{A}_{\mathrm{ob}}}{\pi \mathrm{r}^{2}}=\frac{\theta}{\pi}-\frac{1}{\pi} \cos \theta \sin \theta
$$

and therefore the fraction of energy transmitted is

$$
\mathrm{f}=1-\frac{\mathrm{A}_{\mathrm{ob}}}{\pi^{2}}=1-\frac{\theta}{\pi}+\frac{1}{\pi} \cos \theta \sin \theta .
$$

The angle $\theta$ can be expressed in terms of $x$ in Figure 3 and so Equation 6 becomes

$$
f=1-\frac{1}{\pi} \arccos \left(1-\frac{x}{r}\right)+\frac{1}{\pi}\left(1-\frac{x}{r}\right) \sqrt{\frac{2 x}{r}-\frac{x^{2}}{r^{2}}} .
$$

The change in the fraction of transmitted light energy with respect to the cylinder location can be determined by calculating the derivative of $\mathrm{f}$ in Equation 7 with respect to $\mathrm{x}$. This gives the slope of the transmitted energy with respect to cylinder location and from Equation 7 the result is

$$
\frac{d f}{d x}=\frac{2 x}{\pi r^{2}}\left[\frac{x / r-2}{\sqrt{\frac{2 x}{r}-\frac{x^{2}}{r^{2}}}}\right] .
$$

When the cylinder is located at $\mathrm{x}=\mathrm{r}$ it can be seen from Equation 7 that the fraction of transmitted light energy is

$$
\mathrm{f}_{\mathrm{x}=\mathrm{r}}=1 / 2
$$

and the slope of transmitted energy versus $x$ at $x=r$ is obtained from Equation 8 as

$$
\left.\frac{\mathrm{df}}{\mathrm{dx}}\right|_{\mathrm{x}=\mathrm{r}}=-\frac{2}{\pi \mathrm{r}} .
$$




\section{Measurements With a Convergent Light Beam}

The light emitted by the $100-\mu \mathrm{m}$ diameter fiber in Figure 2 is divergent with an included angle of approximately 25.4 degrees. Therefore, a positive lens was used to transform the light into a slightly convergent beam so that an adequate light level would be registered by the light meter from the receiving fiber. A lens of high refractive index material (LaSF9) was chosen for this purpose. Placement of the 3-mm diameter sphere-lens at a distance of $1.0 \mathrm{~mm}$ from the emitting fiber face resulted in a maximum transfer of energy to the receiving fiber when its face was at distance $3.5 \mathrm{~mm}$ from the exit face of the sphere lens as shown in Figure 4.

The unobstructed light beam energy was measured as $6.2 \mu \mathrm{W}$. The transmitted energy was measured at frequent intervals as a cylindrical ferrule 0.119 inch in diameter was moved through the path of the light beam. A plot of the ratio of transmitted light energy to the unobstructed value, as a function of the cylinder movement $\mathrm{x}$, is provided in Figure 5. Also given in Figure 5 (open circles) are the corresponding measurements made as a pin of diameter only 0.009 inch in diameter was moved through the light beam. In both cases the cylindrical ferrule and the pin were moved through the beam along a path midway between the exit face of the lens and the receiving fiber face, i.e., at a distance $1.75 \mathrm{~mm}$ from the receiving fiber face. Taking into account the focal length of the lens and the object/image distances involved, the calculated beam diameter in the plane midway between the lens face and receiving fiber face is approximately 0.012 inch. The solid curve in Figure 5 was obtained from Equation 7 with $r=0.012 / 2=0.006$ inch. Note that both sets of data fit the calculated curve well in the approximate range $20 \%$ to $80 \%$ of the unobstructed light energy. The slight departure

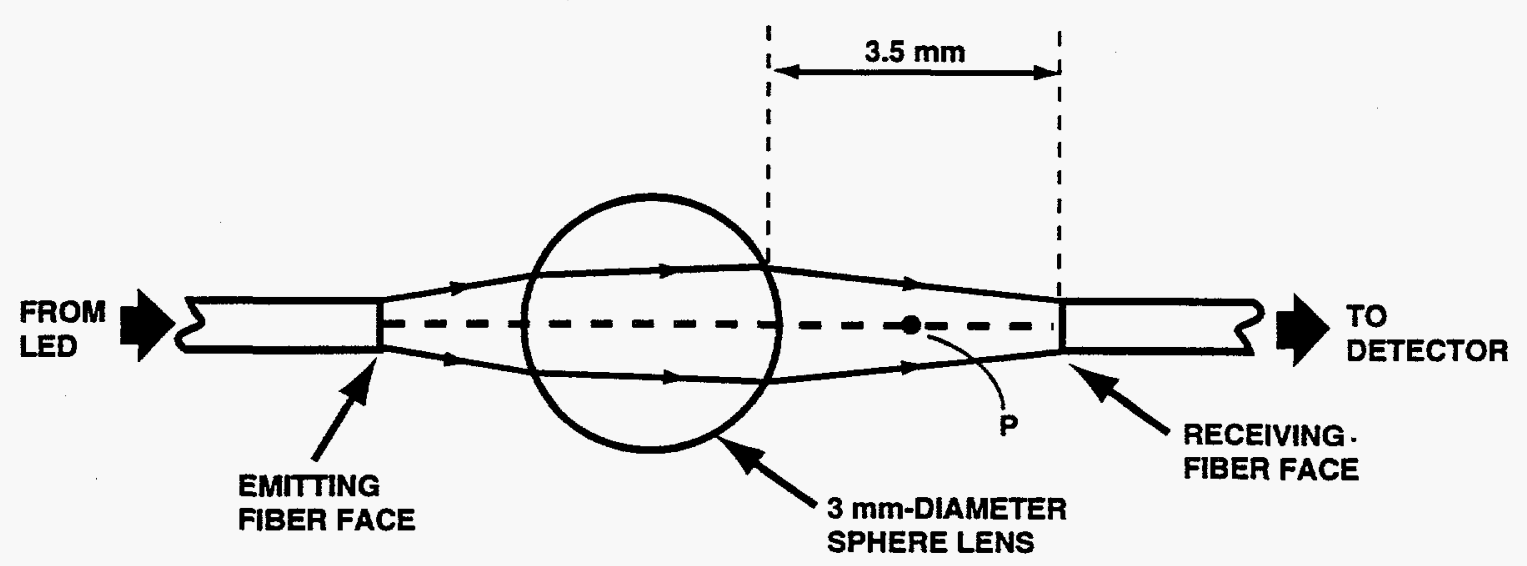

Figure 4. Schematic View of the Arrangement Used to Provide a Slightly Convergent Light Beam, in the Setup of Figure 2, Through Which the Cylindrical Body Passes. (The $x$-axis of Figure 2 is perpendicular to the plane of the page at point $P$.) 


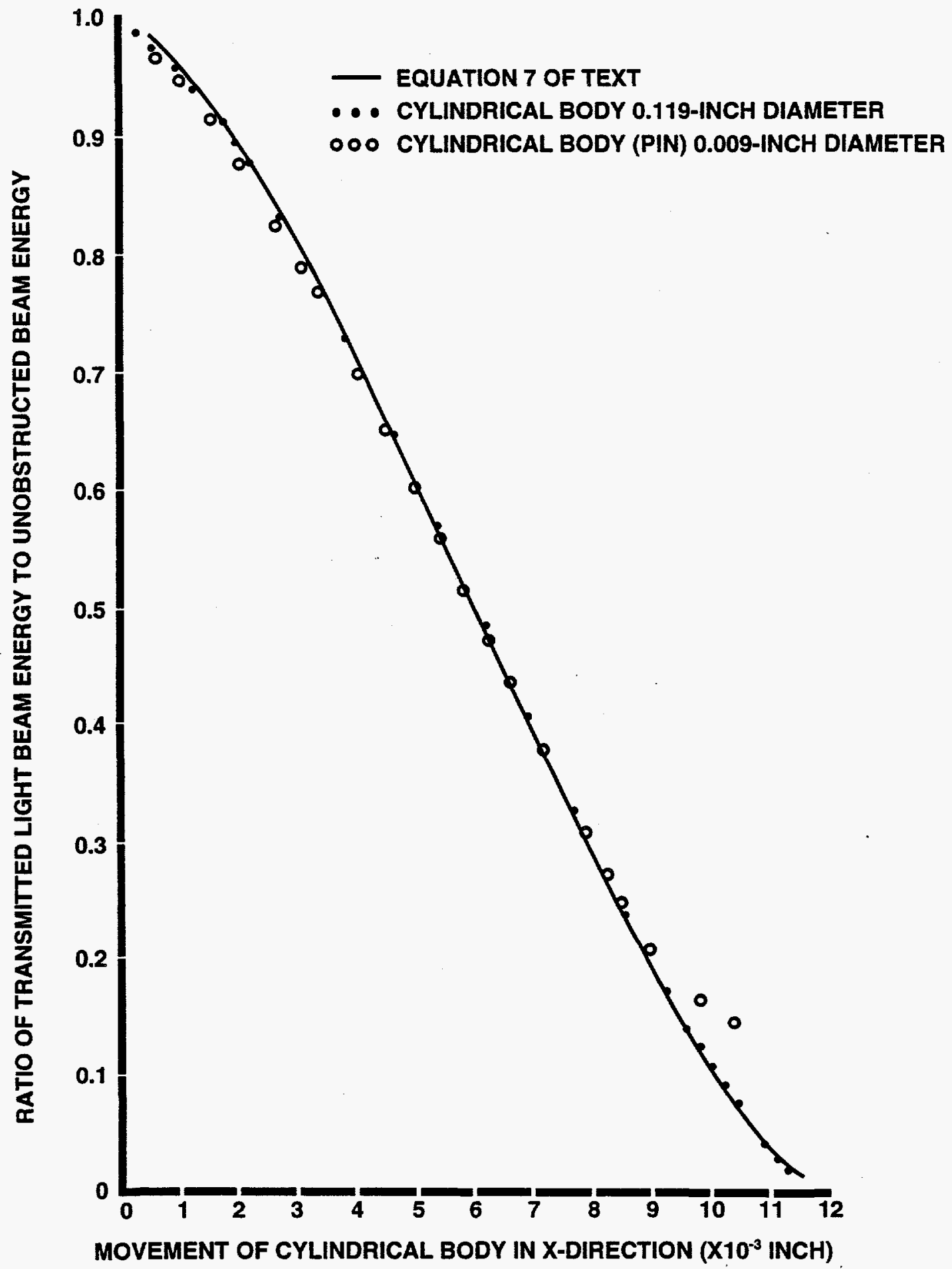

Figure 5. Theoretical and Measured Ratio of Transmitted Light Beam Energy to Unobstructed Beam Energy as a Function of Position of Cylindrical Body in Path of Light Beam 
of the measured points for ratios outside the values occurs because the calculated ratio from Equation 7 is based on the assumption that the light beam is of uniform intensity, which is not quite true unless the optical fiber is fully excited in all its modes, but this is not expected for the short fiber length used. Furthermore, the solid curve assumes that the beam diameter is constant in the plane through which the cylinder and pin are moved, which is not quite true because of the slight convergence introduced by the lens. However, Equation 7 does fit the data points well for both the 0.119 -inch diameter cylinder and the 0.009 -inch diameter pin, over a broad range of measured light ratio above and below the $50 \%$ value, which corresponds to the cylinder or pin positioned midway in the path of the beam.

\section{Repeatability Measurements}

\section{Passage of 0.119-Inch Diameter Ferrule In/Out of Light Beam}

An optical connector with a 0.119 -inch diameter ferrule, as measured with a micrometer caliper, was positioned on the stage of the arrangement in Figure 2; and a study was made to determine the repeatability with which the $x$-coordinates of passage of the ferrule into and out of the beam could be measured using a set target value of 0.500 times the measured unobstructed light beam energy. This was done as follows. With the ferrule moved well out of the path of the light beam, the receiving fiber, at distance $3.5 \mathrm{~mm}$ from the lens, was adjusted in the vertical plane so that a maximum reading was achieved on the HP $8153 \mathrm{~A}$ lightwave meter. This ensured that the receiving fiber was properly aligned with respect to the lens and emitting fiber. The measured energy was $6.22 \mu \mathrm{W}$. Next, the horizontal slide was moved such that the ferrule entered the path of the light beam and began to obstruct the transmitted energy, thereby reducing the reading on the HP 8153A meter. The horizontal slide was advanced until the reading was exactly one half the unobstructed value, i.e., until a reading of $3.11 \mu \mathrm{W}$ was achieved. At this point the interferometer reading was recorded, giving the x-coordinate of the ferrule location. Then the horizontal slide motion was resumed, moving the ferrule farther into the beam. As this occurred, the transmitted energy reading eventually decreased to zero. Further movement of the ferrule in the same direction finally resulted in an increasing transmitted energy reading as the ferrule began to move out of the path of the beam. Motion was stopped when a transmitted energy reading of $3.11 \mu \mathrm{W}$ was again achieved, and the interferometer reading was again recorded. After this, the slide motion was reversed to bring the ferrule back through the light beam to a position not obstructing the beam. The sequence was then repeated and the interferometer reading was recorded as the ferrule passed into the beam to the point of reducing the energy to $3.11 \mu \mathrm{W}$; the interferometer reading was again recorded as the ferrule passed through to the other side, resulting in an increase again to $3.11 \mu \mathrm{W}$ of transmitted energy. In all, thirteen sets of measurements were made and the results are presented in Table 1. It should be noted that the interferometer measurement system for tracking interference fringes in the interferometer beam reflected from the mirror on the slide in Figure 2 was energized with the slide positioned arbitrarily, but sufficiently remote that the ferrule did not obstruct the light beam. Therefore, the interferometer readings given in Table 1 for each trial are referenced to an arbitrary zero slide 
Table 1. Repeatability Measurements for Passage of a 0.119-Inch Diameter Ferrule In/Out of Fiber Light Beam (All values are in microinches.)

\begin{tabular}{llll} 
Trial & $\begin{array}{l}\text { Interferometer Reading } \\
\text { for Passage of Ferrule } \\
\text { Into Light Beam } \\
\mathrm{x}_{1}\end{array}$ & $\begin{array}{l}\text { Interferometer Reading } \\
\text { for Passage of Ferrule } \\
\text { Out of Light Beam }\end{array}$ & $\begin{array}{l}\text { Coordinate of } \\
\text { Ferrule Center } \\
\left(\mathbf{x}_{1}+\mathrm{x}_{2}\right) / 2\end{array}$ \\
\hline 1 & 2,772 & 122,268 & 62,520 \\
2 & 2,778 & 122,265 & $62,521.5$ \\
3 & 2,774 & 122,265 & $62,519.5$ \\
4 & 2,773 & 122,265 & 62,519 \\
5 & 2,774 & 122,267 & $62,520.5$ \\
6 & 2,772 & 122,264 & 62,518 \\
7 & 2,773 & 122,263 & 62,518 \\
8 & 2,770 & 122,261 & $62,515.5$ \\
9 & 2,766 & 122,257 & $62,511.5$ \\
10 & 2,769 & 122,259 & 62,514 \\
11 & 2,768 & 122,258 & 62,513 \\
12 & 2,768 & 122,258 & 62,513 \\
13 & 2,769 & 122,259 & 62,514 \\
\hline
\end{tabular}

$$
\begin{aligned}
& \text { Average }=62,516.73 \mu \text { in. } \\
& \sigma=3.35 \mu \text { in. }
\end{aligned}
$$

location in the x-coordinate direction. However, for a given set of readings, one half the . difference added to the lower reading gives the location of the ferrule center along the $\mathrm{x}$-direction corresponding to the ferrule being centered in the path of the light beam.

Note that the standard deviation for the repeatability of measured location of the center of the ferrule is only $\sigma=3.35 \mathrm{~min}$. 


\section{Passage of an 0.018-Inch Diameter Pin In/Out of the Light Beam}

A similar study of the type leading to the repeatability data of Table 1 was made using a much smaller cylindrical body in the form of an optical fiber of diameter 0.018 inch. To this end the optical fiber was inserted in a ferrule and the combination was mounted on the horizontal slide in the arrangement of Figure 2. The vertical slide was adjusted so that, as the horizontal slide was moved in the x-direction, the 0.018 -inch diameter "pin" passed through the light beam. A total of 15 measurements of the coordinates $x_{1}$ and $x_{2}$ were made for passage of the pin into and out of the light beam. The resulting data are presented in Table 2.

Table 2. Repeatability Measurements for Passage of an 0.018-Inch Diameter Pin/In/Out of the Fiber Light Beam (All values are in microinches.)

\begin{tabular}{llll} 
Trial & $\begin{array}{l}\text { Interferometer Reading } \\
\text { for Passage of Pin } \\
\text { Into Light Beam }\end{array}$ & $\begin{array}{l}\text { Interferometer Reading } \\
\text { For Passage of Pin } \\
\text { Out of Light Beam }\end{array}$ & $\begin{array}{l}\text { Coordinate of } \\
\text { Pin Center } \\
\left(\mathrm{x}_{1}+\mathrm{x}_{2}\right) / 2\end{array}$ \\
\hline 1 & $\mathrm{x}_{1}$ & $\mathrm{x}_{2}$ & 65,802 \\
2 & 56,714 & 74,890 & $65,800.5$ \\
3 & 56,710 & 74,891 & $65,801.5$ \\
4 & 56,715 & 74,888 & 65,799 \\
5 & 56,709 & 74,889 & $65,799.5$ \\
6 & 56,712 & 74,887 & 65,798 \\
7 & 56,706 & 74,890 & $65,795.5$ \\
8 & 56,708 & 74,883 & 65,798 \\
9 & 56,707 & 74,889 & 65,792 \\
10 & 56,705 & 74,879 & $65,792.5$ \\
11 & 56,704 & 74,881 & 65,796 \\
12 & 56,709 & 74,883 & 65,797 \\
13 & 56,708 & 74,886 & $65,794.5$ \\
14 & 56,708 & 74,881 & 65,797 \\
15 & 56,708 & 74,886 & 65,800 \\
\hline
\end{tabular}

Average $=65,797.53 \mu$ in

$\sigma=3.04 \mu$ in. 


\section{Center of an 0.018-Inch Diameter Pin Relative to Center of 0.119-Inch Diameter Ferrule Containing the Pin}

For the repeatability study of measuring the concentricity of the hole in a ferrule relative to the outer ferrule diameter, a ferrule of diameter 0.119 inch was used. A pin of diameter 0.018 inch was found to fit very snugly in the ferrule hole. The combination was placed on the combined horizontal/vertical stages of the arrangement in Figure 2, with the ferrule/pin combination at an arbitrary orientation about its vertical axis. The orientation remained fixed throughout the series of repeatability measurements.

With the horizontal slide positioned so that the ferrule was close to the edge of the light beam, but not obstructing any portion of the light beam, the interference-fringe measurement system of the Hewlett-Packard laser interferometer was energized, corresponding to an arbitrary zero reference point along the $\mathrm{x}$-axis of Figure 2. Next, the light energy coupled from one fiber to the other was measured with the Hewlett-Packard lightwave multimeter and found to be $6.26 \mu \mathrm{W}$. The horizontal slide was moved until the ferrule obstructed the light beam such that the transmitted light energy was reduced to $3.13 \mu \mathrm{W}$, or one half the unobstructed value, and the corresponding interferometer reading was measured as $x_{1}=4,479 \mu$ in., relative to the arbitrary zero-distance reference referred to above. Note this entry for $x_{1}$ under Trial No. 1 in the data of Table 3. Next, the vertical stage in Figure 2 was adjusted downward $3.00 \mathrm{~mm}$ so that, upon continued movement of the horizontal slide in the $\mathrm{x}$-direction, the pin would pass through the path of the light beam. Accordingly, the horizontal slide was moved until the pin obstructed the transmitted beam energy to the one-half value, or $3.13 \mu \mathrm{W}$. The corresponding interferometer reading gave $x_{2}=55,934 \mu$ in., which is entered for Trial 1 in Table 3 . The horizontal slide movement was continued until the pin passed through the beam to the point at which the transmitted light beam energy increased to the level of $3.13 \mu \mathrm{W}$, at which the interferometer reading gave the value of $x_{3}=74,108 \mu \mathrm{in}$. listed for Trial 1 . The vertical slide was then raised $3.00 \mathrm{~mm}$, back to its original vertical position so that, upon continued movement of the horizontal slide the ferrule would begin to pass out of the path of the light beam, thereby allowing the transmitted light energy to begin to rise. So, movement of the horizontal slide was continued until the transmitted light beam energy rose to the one-half value of $3.13 \mu \mathrm{W}$, and the interferometer reading giving the $\mathrm{x}$-coordinate was recorded. This reading is listed as $\mathrm{x}_{4}$ for Trial 1 in Table 3. 
Table 3. Measurement Repeatability for Location of an 0.018-Inch Diameter Pin Center Relative to Center of a 0.119-Inch Diameter Ferrule Containing the Pin. (All values are in microinches.)

\begin{tabular}{|c|c|c|c|c|c|c|c|}
\hline & & & & & $x_{F}=$ & $x_{p}=$ & \\
\hline Trial & $x_{1}$ & $\underline{x}_{2}$ & $\underline{x}_{3}$ & $x_{1}$ & $\left(x_{1}+x_{4}\right) / 2$ & $\left(\mathrm{x}_{2}+\mathrm{x}_{3}\right) / 2$ & $\mathrm{C}=\mathrm{x}_{\mathrm{P}}-\underline{\mathrm{x}}_{\underline{\underline{F}}}$ \\
\hline 1 & 4,479 & 55,934 & 74,108 & 123,975 & 64,227 & 65,021 & 794 \\
\hline 2 & 1,911 & 53,358 & 71,535 & 121,404 & $61,657.5$ & $62,446.5$ & 789 \\
\hline 3 & 1,149 & 52,600 & 70,778 & 120,649 & 60,899 & 61,689 & 790 \\
\hline 4 & 1,091 & 52,540 & 70,721 & 120,587 & 60,839 & $61,630.5$ & 791.5 \\
\hline 5 & 1,176 & 52,623 & 70,801 & 120,671 & $60,923.5$ & 61,712 & 788.5 \\
\hline 6 & 1,650 & 53,093 & 71,268 & 121,141 & $61,395.5$ & $62,180.5$ & 785 \\
\hline 7 & 809 & 52,254 & 70,431 & 120,300 & $60,554.5$ & $61,342.5$ & 788 \\
\hline 8 & 568 & 52,020 & 70,194 & 120,058 & 60,313 & 61,107 & 794 \\
\hline 9 & 1,039 & 52,489 & 70,664 & 120,526 & $60,782.5$ & $61,576.5$ & 794 \\
\hline 10 & 430 & 51,882 & 70,062 & 119,927 & $60,178.5$ & 60,972 & 793.5 \\
\hline
\end{tabular}


The $x$-coordinate corresponding to the center of the ferrule in the path of the light beam is $\mathrm{x}_{\mathrm{F}}=\left(\mathrm{x}_{1}+\mathrm{x}_{4}\right) / 2$, and this value is $64,227 \mu \mathrm{in}$., relative to the arbitrary zero reference distance for Trial 1 , as can be seen from Table 3. Likewise, the $x$-coordinate for the center of the pin in the path of the beam is $\left(x_{2}+x_{3}\right) / 2$ and this is listed under $x_{p}$ for Trial 1. Therefore, the concentricity, C, for Trial 1 is merely $x_{P}-x_{F}$, which is $794 \mu$ in. for Trial 1 .

The measurement of $\mathrm{C}$ was repeated nine additional times, for a total of ten complete sets of measurements. The data for all ten trials are given in Table 3. For each trial, the zero reference reading of the interferometer was set arbitrarily, as mentioned above. The average measured value of $\mathrm{C}$ is $790.75 \mu \mathrm{in}$., and the corresponding standard deviation of the ten sets of data is $\sigma=3.15 \mu$ in.

In conclusion of the discussion concerning the data of Table 3 , it should be noted that each of the entries for $\mathrm{x}_{2}$ and $\mathrm{x}_{3}$ includes a small correction factor related to a small change in $\mathrm{x}$-coordinate reading during the movement of the vertical slide to position the pin into and out of the path of the light beam. The correction arises as follows. When the vertical slide is moved to position the pin in the path of the beam, the interferometer reading for the x-coordinate shifts slightly because the plane of the mirror from which the interferometer beam is reflected is not necessarily exactly perpendicular to the axis of the interferometer beam. As a result, when the vertical slide is moved, the point of reflection of the interferometer beam on the mirror moves slightly toward or away from the interferometer even though the horizontal slide remains unmoved. This is of no consequence in the overall measurement provided the small shift is measured and taken into account by applying it to the indicated values of $x_{2}$ and $x_{3}$. For the data referenced in Table 3 , in which the vertical slide was moved down $3.00 \mathrm{~mm}$ to position the pin in the path of the light beam, and then later moved up by the same amount to position the ferrule in the light beam path, the measured shift in interferometer reading in the $\mathrm{x}$-coordinate horizontal direction was $318 \mu$ in. Each of the values for $\mathrm{x}_{2}$ and $\mathrm{x}_{3}$ listed in Table 3 have been corrected for this shift.

\section{Concentricity Measurement as a Function of Angular Orientation of Cylindrical Ferrule About Its Vertical Axis}

The repeatability data in Table 3 are for a fixed orientation of the ferrule about its vertical axis, and therefore the concentricity measurement is in a fixed plane of the ferrule.

Consider the arrangement in Figure 6a in which the ferrule is oriented such that the line joining the center of the ferrule and the center of the hole is parallel to the $\mathrm{x}$-axis of the horizontal slide travel in Figure 2. In this case the measured concentricity is the maximum separation of ferrule and hole centers. If the ferrule orientation is $180^{\circ}$ from that in Figure 6a, as shown in Figure 6b, 


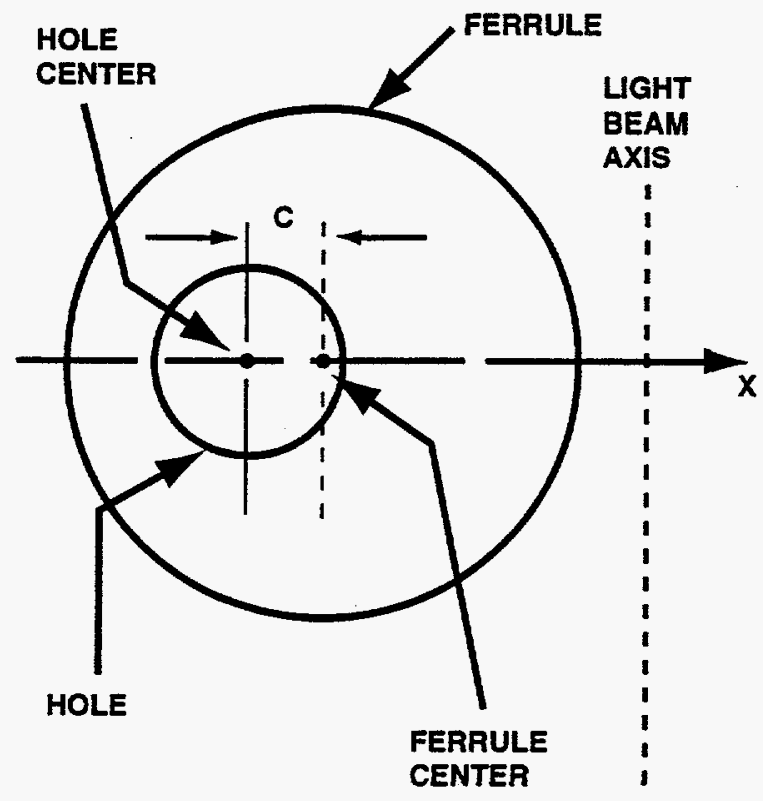

(a)

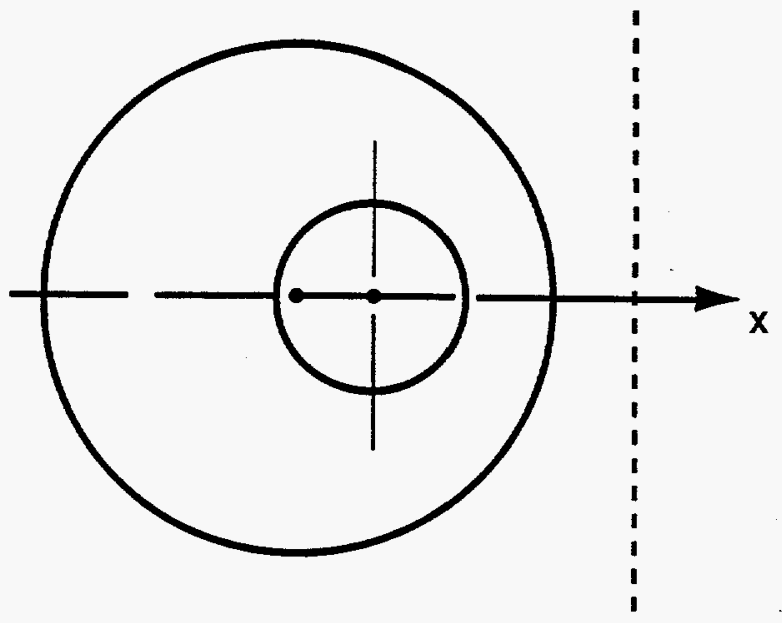

(b)

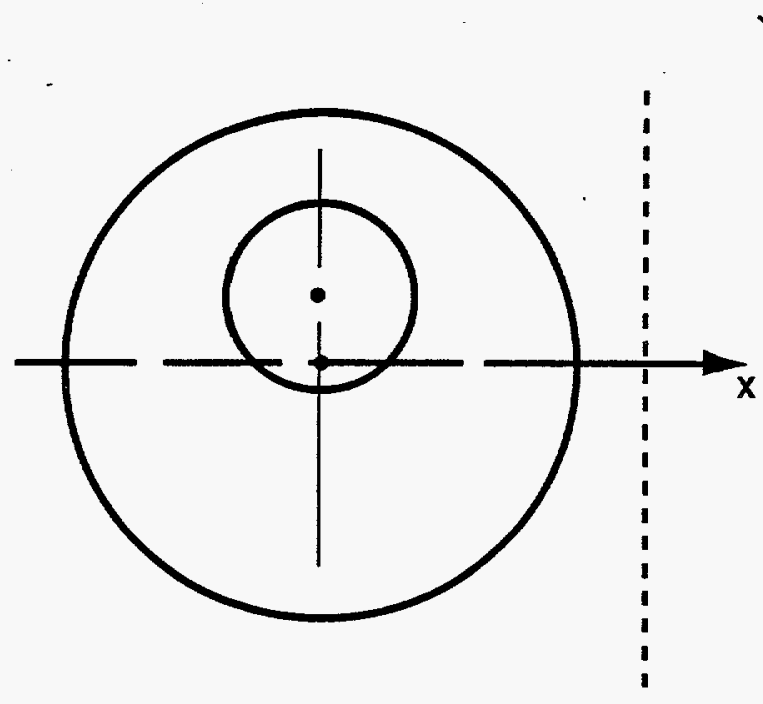

(c)

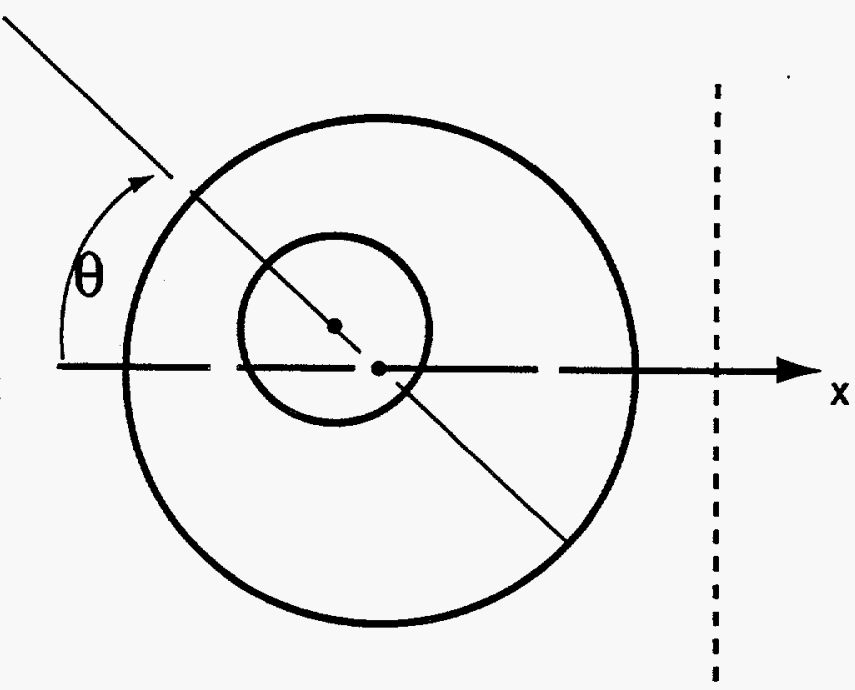

(d)

Figure 6. Cross Section of a Ferrule Containing a Hole Whose Degree of Concentricity is the Distance $C$. (The direction of the horizontal slide travel in Figure 2 is designated by the line denoted by " $x$ " in each view above.) 
then the measured concentricity will have the same magnitude as in Figure 6a, but opposite sign. If the ferrule orientation is $90^{\circ}$ from that in Figure 6a, then the arrangement is that depicted in Figure $6 \mathrm{c}$; and it is clear for this particular orientation that the measured separation between ferrule and hole centers in this plane will be zero. Therefore, for an arbitrary orientation of the ferrule about its vertical axis, as shown in Figure $6 \mathrm{~d}$, the measured concentricity is

$$
\mathrm{C}_{\mathrm{m}}=\mathrm{C} \cos \theta
$$

where $\theta$ is the angle between the $\mathrm{x}$-axis in Figure 2 and the line joining the ferrule and hole centers. If $\theta$ is $0^{\circ}$ or $180^{\circ}$, then $C_{m}$ is $\pm C$, respectively, and $C_{m}=0$ for $\theta=90^{\circ}$, as described above.

In general, when a ferrule is placed on the horizontal slide in Figure 1, the line joining the ferrule and hole centers is oriented at an arbitrary angle $\theta$ with respect to the $\mathrm{x}$-axis. Hence the "phase angle" $\phi$ can be incorporated in Equation 10 to give

$$
\mathrm{C}_{\mathrm{m}}=\mathrm{C} \cos (\theta+\phi) \text {. }
$$

As a test of the above relationship, a ceramic ferrule with a short segment of glass fiber fitting the hole snugly was placed on the horizontal slide in the arrangement of Figure 2, with the ferrule in an arbitrary angular orientation about its vertical axis. Following the procedure described earlier, with reference to data in Table 3 , the concentricity for this arbitrary plane was measured. The ferrule then was rotated through one-sixteenth of a revolution, or $221 / 2^{\circ}$, and the concentricity was measured in the new plane. This procedure was repeated in rotational increments of $221 / 2^{\circ}$ about the vertical, until a complete revolution of the ferrule about its vertical axis was completed.

The measured concentricity values are plotted in Figure 7, as a function of the angular increments of $221 / 2^{\circ}$ at which the measurements were made. The solid curve is a best fit of the data, obtained from Equation 11 with $\mathrm{C}=190 \mu \mathrm{in}$. In fitting Equation 11 to the data, it was found that the phase angle $\phi$ was $32.8^{\circ}$.

\section{Measurements With a Collimated Light Beam}

The arrangement is shown schematically in Figure 8. A lens in the form of a full sphere of diameter $3.0 \mathrm{~mm}$ was placed relative to the exit face of the optical fiber so that a quasi-collimated beam is formed. The lens material was LaSF9, which is a Schott glass with refractive index 1.83 at the light-emitting diode (LED) wavelength of $846 \mathrm{~nm}$. Therefore, based on the thick-lens equation, the distance between the sphere lens center and the exit fiber face is $1.665 \mathrm{~mm}$, which corresponds to a gap of $0.165 \mathrm{~mm}(0.0065 \mathrm{in}$.) between the fiber face and the nearest point on the 


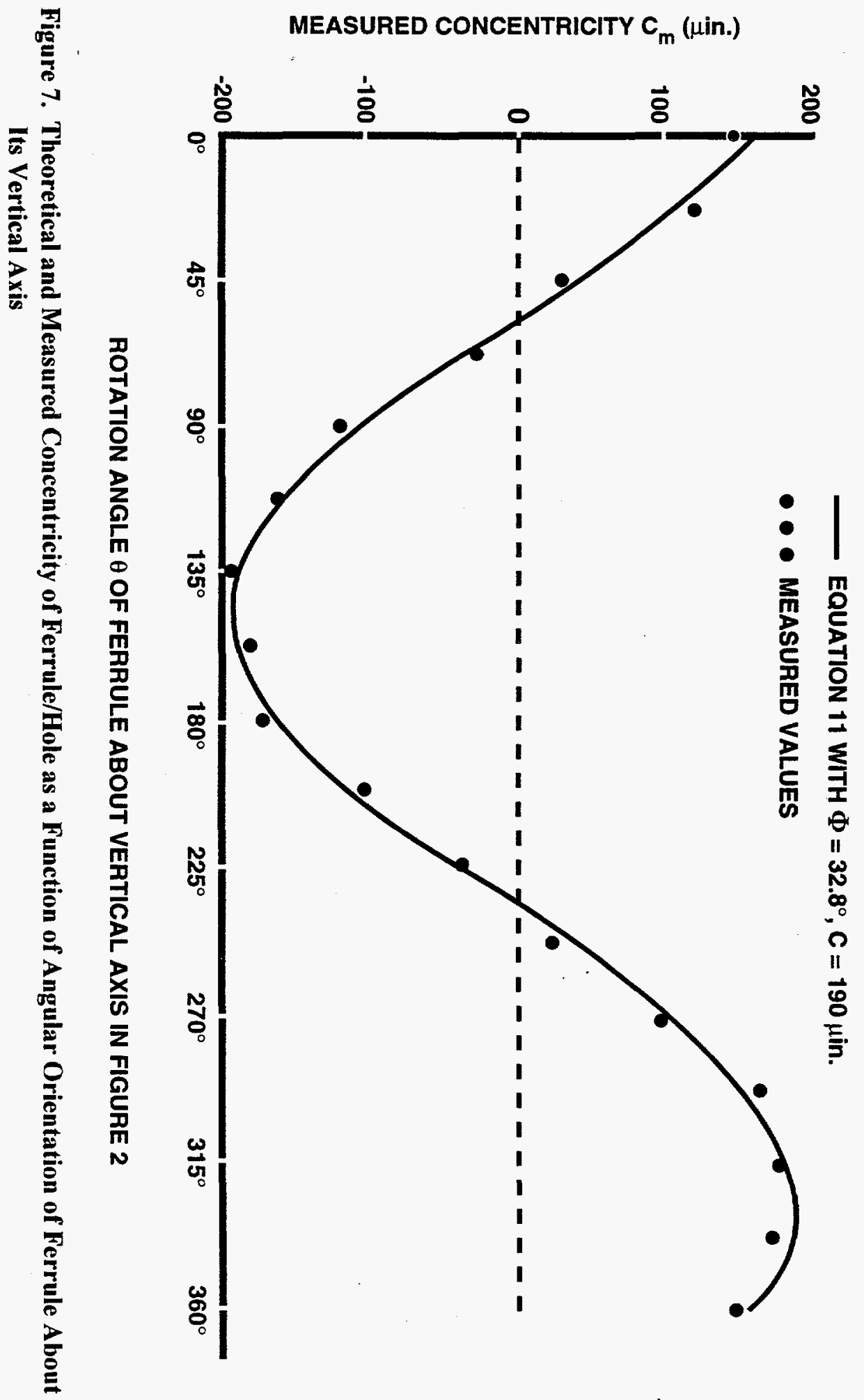




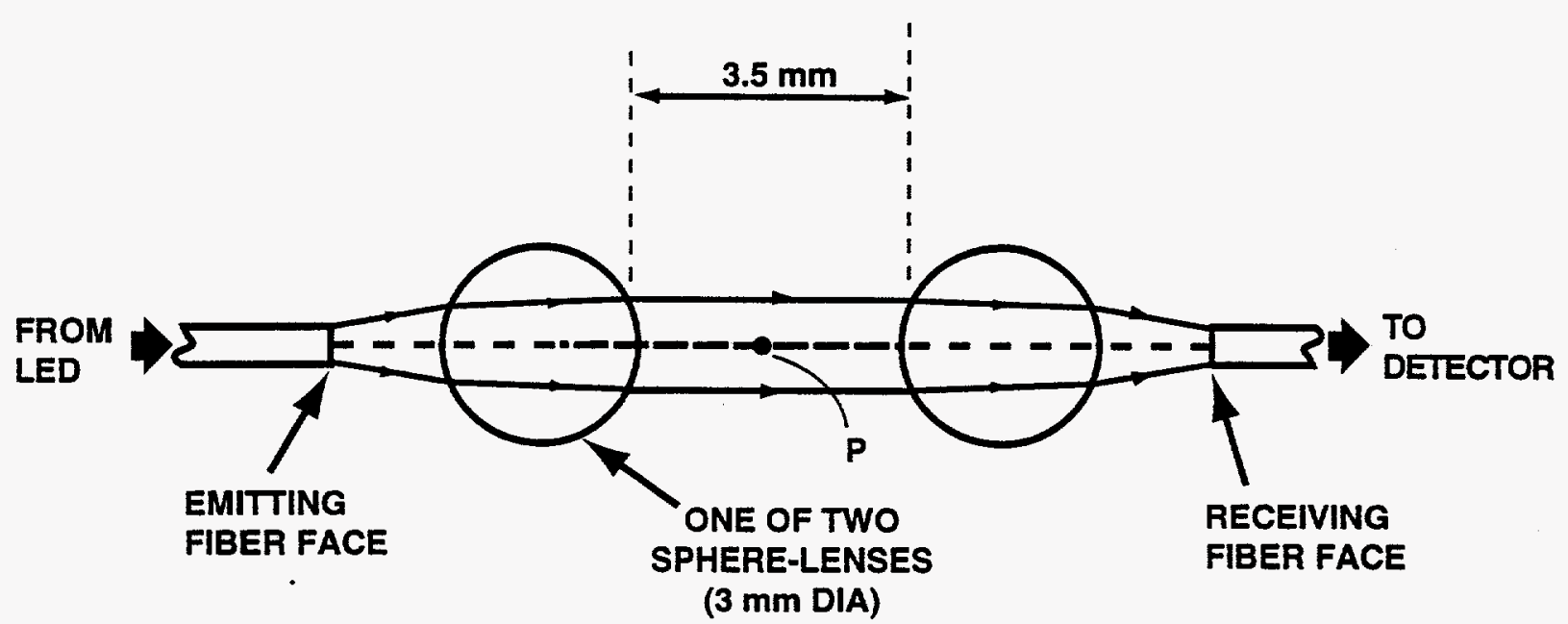

Figure 8. Schematic View of Lens/Fiber Arrangement for Providing a Collimated Light Beam, in the Setup of Figure 2, Through Which the Cylindrical Body Passes. (The x-axis of Figure 2 is perpendicular to the plane of the page at point $P$, above.)

sphere-lens. A second lens of the same size and type was placed at the same distance from the receiving fiber face and hence this lens focuses the quasi-collimated beam on the receiving fiber face. Because the beam in the region between the two lenses is collimated, or nearly so, the distance between the two is not critical, although it is best to keep the distance small. Accordingly, the fibers and lenses were positioned with a gap of $3.5 \mathrm{~mm}$ between the nearest points on the lens surfaces. This allowed adequate room for passage of a ferrule of diameter 0.119 inch $(3 \mathrm{~mm})$.

\section{Repeatability Measurements of the Concentricity of an 0.0848-Inch Diameter Ferrule Relative to Its 0.0188-Inch Diameter Hole}

The transmitted light level in the unobstructed beam with this arrangement was measured at $7.02 \mu \mathrm{W}$. A ferrule of diameter 0.0848 inch containing a hole in which a pin of diameter 0.0188 inch fit snugly was placed on the horizontal slide. The angular orientation of the ferrule about its vertical axis was arbitrary but remained fixed throughout the course of the repeatability measurements.

The repeatability study was performed in a manner similar to that with the convergent beam. First, the horizontal slide was moved until the ferrule obstructed the light beam to the point at which the transmitted light level was reduced to $3.51 \mu \mathrm{W}$, or one half the unobstructed value. The interferometer reading was recorded, giving the coordinate $x_{1}$ of the horizontal slide position. Next, the vertical slide was lowered just enough so that the pin would pass through the light beam as the horizontal slide was moved further in the same sense along the x-direction. Accordingly, as the movement was continued until the pin obstructed the light beam such that the transmitted light level was $3.51 \mu \mathrm{W}$, or half the unobstructed level, the corresponding interferometer reading gave the coordinate $\mathrm{x}_{2}$. The horizontal slide movement was continued as 
the light level dropped to zero, corresponding to total obscuration by the pin, and then began to rise as the pin began to move out the other side of the beam. The horizontal slide motion was ceased when the light level again reached $3.51 \mu \mathrm{W}$, and the interferometer reading was recorded as $x_{3}$. At this point the vertical slide was raised by the same amount it had been lowered earlier, so that the ferrule would pass again in the path of the light beam. Then, the horizontal slide was moved further in the same direction along the $\mathrm{x}$-axis until the ferrule began to pass out of the light beam path, and the motion was ceased when the transmitted light level again reached $3.51 \mu \mathrm{W}$. The interferometer reading was recorded as $\mathrm{x}_{4}$, corresponding to the "far position" of the ferrule in the light beam.

The foregoing procedure was repeated so that ten sets of measurements were obtained. The data are tabulated in Table 4 . The average value of concentricity measured in this plane of the ferrule/pin combination is $83.45 \mu \mathrm{in}$., with a standard deviation of $2.37 \mu \mathrm{in}$.

\section{Concentricity Measurements Based on Slope of Transmitted Light Level Versus Horizontal Slide Position}

For positions of the ferrule or pin such that the transmitted light level is in the approximate range of $50 \% \pm 30 \%$ of the unobstructed light level, the transmitted light is very nearly linearly dependent on the $\mathrm{x}$-coordinate of the horizontal slide position. Therefore, in this range of ferrule or pin position, the transmitted power can be written in the form

$$
\mathrm{P}=\mathrm{Mx}+\mathrm{b},
$$

where $M$ is the slope of the straight line and $b$ is the intercept on the transmitted light level-axis. Let $\mathrm{M}_{\mathrm{I}}$ and $\mathrm{b}_{\mathrm{I}}$ be the slope and intercept of a best-fit straight line through a series of measured transmitted light levels, $\mathrm{P}$, as a function of movement of the ferrule into the path of the light beam, and let $\mathrm{M}_{\mathrm{IV}}$ and $\mathrm{b}_{\mathrm{IV}}$ be the slope and intercept of a best-fit straight line through a series of measured light levels as a function of movement of the ferrule out of the light beam. Then, according to Equation 12, the curves representing movement of the ferrule into and out of the light beam can be expressed as

$$
\begin{aligned}
& P=M_{I} x+b_{I} \\
& P=M_{I V} x+b_{I V} .
\end{aligned}
$$

As the ferrule moves into the light beam, the transmitted light level decreases and hence the slope $M_{I}$ is negative, whereas $M_{I V}$ is positive because the light level increases as the ferrule moves out of the beam. 
Table 4. Measurement Repeatability for Location of a 0.0188-Inch Diameter Pin Center Relative to Center of an 0.0848-Inch Diameter Ferrule Containing the Pin. (All values are in microinches .) Collimated Light Beam

\begin{tabular}{|c|c|c|c|c|c|c|c|}
\hline & & & & & $x_{F}=$ & $x_{p}=$ & \\
\hline Trial & $x_{1}$ & $\mathrm{x}_{2}$ & $x_{3}$ & $\mathrm{x}_{4}$ & $\left(\mathrm{x}_{1}+\mathrm{x}_{4}\right) / 2$ & $\left(\mathrm{x}_{2}+\mathrm{x}_{3}\right) / 2$ & $\mathrm{C}=\mathrm{x}_{\mathrm{F}}-\mathrm{x}_{\mathrm{P}}$ \\
\hline 1 & 9,742 & $43,162.5$ & $61,534.5$ & 95,127 & $52,434.5$ & $52,348.5$ & 86 \\
\hline 2 & 3,243 & $36,668.5$ & $55,022.5$ & 88,622 & $45,932.5$ & $45,845.5$ & 87 \\
\hline 3 & 1,030 & $34,449.5$ & $52,841.5$ & 86,427 & $43,728.5$ & $43,645.5$ & 83 \\
\hline 4 & 789 & $34,208.5$ & $52,599.5$ & 86,190 & $43,489.5$ & 43,404 & 85.5 \\
\hline 5 & 905 & 34,331 & 52,714 & 86,301 & 43,603 & $43,522.5$ & 80.5 \\
\hline 6 & 824 & 34,256 & 52,634 & 86,228 & 43,526 & 43,445 & 81 \\
\hline 7 & 1,028 & 34,447 & 52,835 & 86,420 & 43,724 & 43,641 & 83 \\
\hline 8 & 1,016 & 34,434 & 52,821 & 86,410 & 43,713 & $43,627.5$ & 85.5 \\
\hline 9 & 1,025 & 34,448 & 52,833 & 86,420 & $43,722.5$ & $43,640.5$ & 82 \\
\hline 10 & 633 & 34,056 & 52,441 & 86,026 & $43,329.5$ & $43,248.5$ & 81 \\
\hline
\end{tabular}


In a similar manner, if the subscripts "II" and "III" represent best-fit slopes and intercepts for movement of the pin into and out of the light beam, respectively, then Equation 12 yields the following relations for the pin.

$$
\begin{aligned}
& P=M_{I I} x+b_{I I} \\
& P=M_{I I I} x+b_{I I I}
\end{aligned}
$$

where the slope $M_{I I}$ is negative for pin movement into the beam and $M_{I I I}$ is positive for movement out.

If, as before, $\mathrm{x}_{1}$ and $\mathrm{x}_{4}$ are the $\mathrm{x}$-coordinates of the horizontal slide motion for which the ferrule obstructs half the light level as it moves in and allows half the level to pass as it moves out, then the $x_{1}$ and $x_{4}$ are related to the ferrule diameter through

$$
D_{f}=\left(x_{4}-x_{1}\right)
$$

Therefore, combining Equation 15 with the relations in Equation 13, the transmitted light level $P_{D}$ is

$$
P_{D}=\frac{D_{f} M_{I} M_{I V}+b_{I V} M_{I}-b_{I} M_{I V}}{M_{I}-M_{I V}}
$$

From Equations 13 and 14, combined with Equation 3, the concentricity is

$$
\begin{aligned}
C & =(1 / 2)\left[x_{1}+x_{4}-x_{2}-x_{3}\right] \\
& =(1 / 2)\left\{\frac{P_{D}-b_{1}}{M_{1}}+\frac{P_{D}-b_{I V}}{M_{I V}}-\frac{P_{D}-b_{I I}}{M_{I I}}-\frac{P_{D}-b_{I I I}}{M_{I I I}}\right\},
\end{aligned}
$$

where $P_{D}$ is obtained from Equation 16. A pictorial representation of the results leading to Equation 17 is given in Figure 9.

A series of eight independent runs was made to test the repeatability of determining the concentricity in a fixed plane through the use of Equations 16 and 17. A ceramic ferrule of diameter 0.0848 inch containing a hole in which a glass fiber of diameter 0.0188 inch fit snugly was placed on the horizontal slide. The unobstructed light level was measured as $7.0 \mu \mathrm{W}$. The horizontal slide was moved until the ferrule allowed approximately $80 \%$ of the light to pass, and the light level along with the interferometer reading ( $\mathrm{x}$-coordinate) was recorded. The ferrule was moved farther into the light beam path and another pair of light-level and $\mathrm{x}$-coordinate readings were recorded. This was repeated until the ferrule position allowed approximately 


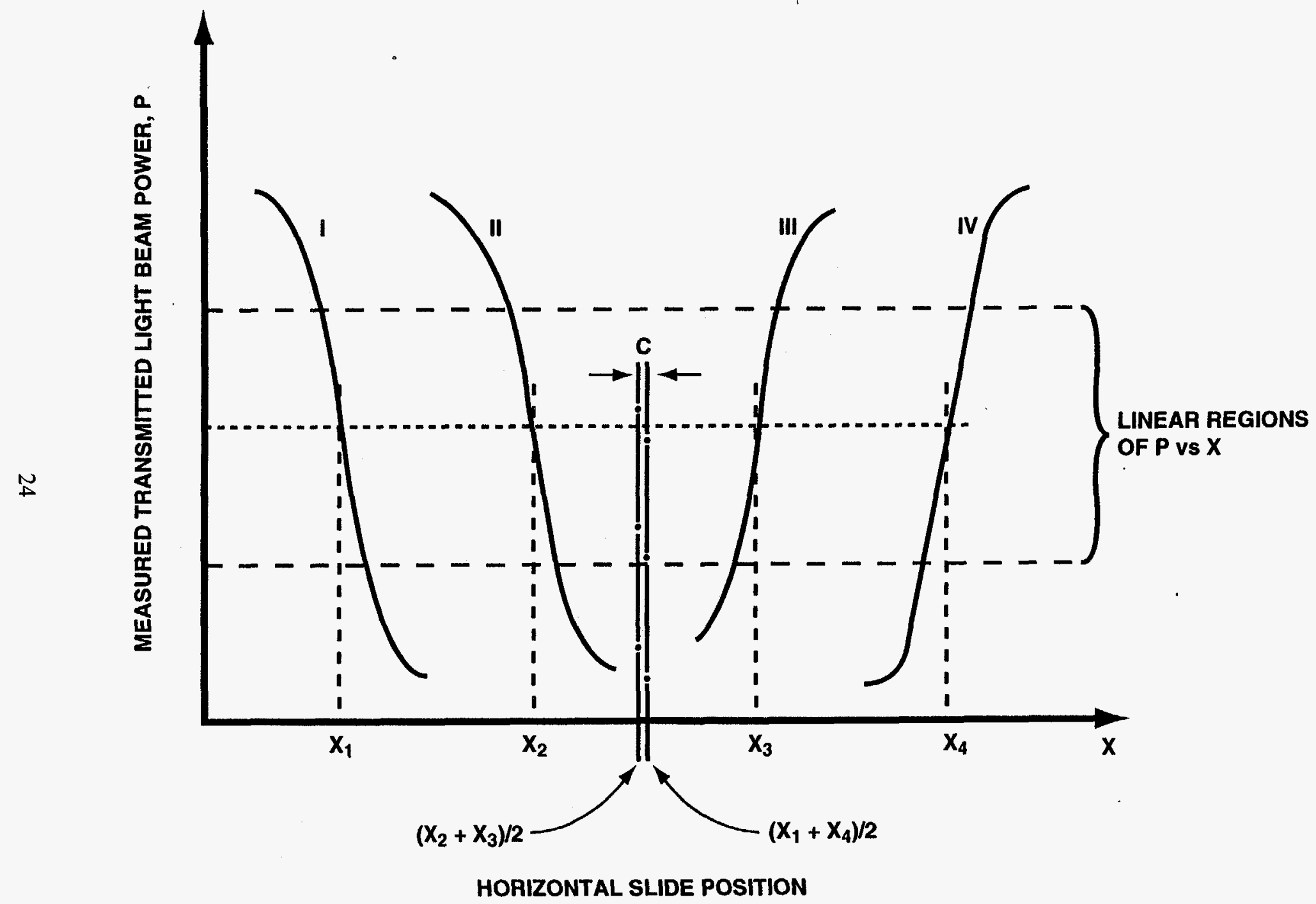

Figure 9. Graphic Representation of Equation 17 of the Text. (Regions I and IV refer to movement of the ferrule into and out of, respectively, the light beam path. Regions II and III represent, respectively, movement of the pin into and out of the light beam path.) 
$20 \%$ of the light to pass. Seven pairs $(\mathrm{P}, \mathrm{x})$ were measured with the light levels nearly equally spaced over the interval $80 \%$ to $20 \%$ of light transmission. A linear regression was performed on the seven pairs of $P$ and $x$ to yield the slope and intercept of the best-fit straight line for obscuration of light as the ferrule was moved into the path of the light beam. The slope and correlation coefficient are listed in the first column, for Trial 1, in Table 5.

Next, the vertical slide was lowered until the glass pin intercepted the light beam for further movement of the horizontal slide in the $\mathrm{x}$-direction. Again, a series of seven transmitted light levels and corresponding $x$-coordinates were measured in the range from approximately $80 \%$ transmission to $20 \%$ transmission, with the measurements made at nearly equally spaced light levels in the interval. The second column for Trial 1 in Table 5 gives the slope and correlation obtained by linear regression giving the best-fit straight line of $P$ versus $x$. Similarly, the third column gives the results of the linear regression for measured light level versus $\mathrm{x}$-coordinate as the pin was moved out of the path of the light beam, for transmission in the approximate range $20 \%$ to $80 \%$.

Finally, the vertical slide was raised to its original position and a series of seven pairs of $(P, x)$ was measured for movement of the ferrule out of the light beam path. A linear regression was performed to give the best-fit straight line, and the results are given in the fourth column for Trial 1 in Table 5. For each of the four regions it can be seen that the correlation is very near unity, indicating that the transmitted light is very nearly linearly related to the horizontal slide position over the transmission range $80 \%$ to $20 \%$.

Using the ferrule diameter $D_{f}=0.0848$ inch along with the slopes and intercepts for the two regions for entry and exit of the ferrule in the light beam path gives a value of $3.44 \mu \mathrm{W}$ from Equation 16 for a $50 \%$ transmitted light level. Likewise, Equation 16 gives a value of $3.6 \mu \mathrm{W}$ when the pin diameter of 0.0188 inch is substituted, along with the slopes and intercepts for entry and exit of the pin in the light beam path. For both diameters, the calculated value is very close to $3.55 \mu \mathrm{W}$, or one half the unobstructed light level. Therefore, the concentricity for Trial 1 was calculated from Equation 17 using the slopes and intercepts from the linear regressions, along with the value $P_{D}=3.55 \mu \mathrm{W}$. The result was $\mathrm{C}=103.5 \mu \mathrm{in}$., which is listed in the last column for Trial 1, Table 5.

A total of eight independent sets of measurements was made, for a fixed orientation of the ferrule about its vertical axis, and the results are tabulated in Table 5. The average value of concentricity is $107.9 \mu \mathrm{in}$., and the standard deviation is $\sigma=4.19 \mu \mathrm{in}$.

Measurements of the slope of the ratio of transmitted energy to unobstructed energy, for $\mathrm{x}$ values in the vicinity of $\mathrm{f}=1 / 2$, agree well with the slope calculated from Equation 10. 
Table 5. Repeatability of Concentricity Measurement in a Given Plane of Ferrule/Pin Based on Equation 17

Slope $M\left(\mu \mathrm{W}\right.$ per mil $\left.{ }^{*}\right)$

Intercept $b(\mu \mathrm{W}) \quad$ Concentricity

Linear Regression Coefficient $c$ Calculated From

Trial Ferrule In

Pin Out

Ferrule Out Equation 17

$\begin{array}{lllll}\mathrm{M} & -0.3626 & -0.3375 & 0.3345 & 0.3629 \\ \mathrm{~b} & 12.864 & 23.480 & -22.379 & -36.766 \\ \mathrm{c} & 0.99978 & 0.99991 & 0.99994 & 0.99980\end{array}$

$$
2
$$

2

M $\quad-0.3665$

b $\quad 5.902$

c

0.99993

$$
-0.3393
$$

17.044

0.99989

$$
0.3350
$$

$-15.961$

0.3668

$-30.133$

0.99989 .

0.99992

$3 \quad \mathrm{M}$

$\begin{array}{ll}\text { M } & -0.3668\end{array}$

b $\quad 6.092$

$-0.3386$

0.3350

17.194

$-16.133$

0.3667

0.99989

0.99988

$-30.311$

0.99991

4

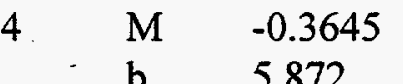

$-0.3389$

0.3349

17.007

$-15.929$

0.3663

$-30.056$

c $\quad 0.99989$

0.99989

0.99987

0.99991

$5 \quad \mathrm{M} \quad-0.3669$

b $\quad 5.652$

$-0.3396$

16.821

0.3347

$-15.707$

0.3671

$-29.897$

0.99988

0.99984

0.99992

6

$\begin{array}{ll}\text { M } & -0.3669 \\ \mathrm{~b} & 5.937\end{array}$

$-0.3388$

17.060

0.3353

$-16.010$

0.3666

$-30.147$

0.99990

0.99990

0.99990

7

M $\quad-0.3679$

b $\quad 5.852$

c $\quad 0.99994$

$-0.3390$

16.979

0.3358

0.99992

$-15.956$

0.99993

0.3671

$-30.098$

0.99993

$8 \quad \mathrm{M}$

$$
\mathrm{b}
$$

$$
-0.3667
$$

5.844

$-0.3391$

16.984

0.3346

$-15.884$

0.3668

$-30.068$

0.99993

0.99989

0.99986

0.99992

${ }^{*} 1 \mathrm{mil}=10^{-3} \mathrm{inch}$

$\mathrm{C}_{\mathrm{AVG}}=107.89 \mu \mathrm{in}$.

$\sigma=4.19 \mu \mathrm{in}$. 


\section{Accomplishments}

A very precise technique was developed for measuring the degree of concentricity of a hole in a cylinder. The work was undertaken in support of advanced optical firing systems, such as DOI, which require high fiber-to-fiber concentricity not only for maximum coupling efficiency, but also to avoid damage to fiber faces at high optical power densities in the range of GW/cm ${ }^{-2}$.

In the method devised in this work, a highly stable light beam approximately $0.3 \mathrm{~mm}$ in diameter is provided with an LED and lenses, and its unobstructed energy is measured with a HewlettPackard Model 8153A lightwave meter. Then, as the cylindrical ferrule of an optical connector is moved into the beam, the decrease in light energy is measured. Likewise, the decrease in light beam energy is measured as a closely fit fiber in the ferrule is moved into the light beam. Next, the increase in light energy is measured as the pin and ferrule, in turn, are moved out of the light beam path. During movement of the ferrule and the fiber, a Hewlett-Packard laser interferometer is used to measure the positions accurately with a resolution of $\pm 0.3937 \mu \mathrm{in}$. The centers of the ferrule and fiber are determined from the combined laser interferometer readings and the corresponding light beam measurements, and this provides a measurement of the difference in ferrule and fiber centers, or concentricity, in the plane of measurement.

Analytic expressions were derived for the decrease in light beam energy as the ferrule, or fiber, is moved into the beam path, thereby partially obscuring the energy. Experimental results agreed with the analysis and showed that the decrease or increase in light beam energy as the cylindrical body (ferrule or fiber) is moved into or out of the beam, respectively, is linearly dependent on the position of the cylinder over the approximate range $20 \%$ to $80 \%$ of transmitted beam energy.

Measurements of the repeatability of concentricity were made with a collimated light beam and also with a slightly convergent light beam. With a collimated light beam, the standard deviation for concentricity measurement was $2.37 \mu \mathrm{in}$. A study with a convergent light beam gave a standard deviation of $3.15 \mu \mathrm{in}$.

By virtue of the measurement technique, the concentricity is measured in one plane of the ferrule, depending on the particular orientation of the ferrule about its longitudinal axis in the setup. An analysis was made showing that the measured concentricity should vary as a cosine function depending on the orientation of the line joining the fiber hole center and the ferrule center, in the light beam. A series of concentricity measurements as a function of ferrule angular orientation gave experimental confirmation of the analysis.

Equations were derived from which the concentricity could be determined based on the slopes and intercepts of best-fit straight lines of decrease and increase of light beam energy as the ferrule (or fiber) was moved, respectively, in or out of the light beam path. Using this method with a collimated light beam, a study showed that the standard deviation for repeatability of the concentricity measurement was $4.19 \mu \mathrm{in}$. In the data leading to this result, the correlation 
coefficients of obscured beam energy versus ferrule (or fiber) position in the linear regression were 0.999 or higher for beam energy transmissions in the range $20 \%$ to $80 \%$.

\section{Future Work}

All the data obtained in this work was through manual movement of the precision horizontal and vertical slides, combined with manual recording of the interferometer readings and the corresponding light beam energy readings. The overall measurement system would lend itself well to automation in which motorized slides could be used along with computer-interfaced printout of the corresponding laser interferometer data and light beam energy. Software could easily be established to provide a printout of the concentricity measurement in an automated system. Automation should be undertaken if the system is to be considered for commercial use in precise concentricity measurements. 


\section{References}

${ }^{1}$ A. Eisele, U. S. Patent No. 3, 732,624, Spindle for Dial Indicator Gauge, May 15, 1973.

${ }^{2}$ G. Dunn, U. S. Patent No. 3,837,085, Range-Extension Device for Double-Probe Hole-Location and Concentricity, September 24, 1974. . 